\title{
Tropical Spiderwort (Commelina benghalensis L.), Identification and Control ${ }^{1}$
}

\section{J. A. Ferrell, G. E. MacDonald, B. J. Brecke ${ }^{2}$ \\ Introduction}

Tropical spiderwort is an annual/perennial weed that has become increasingly common in agronomic production systems. Tropical spiderwort was first observed 8 to 10 years ago by both university researchers and crop producers, but was only found in limited areas. Since this time it has continued to spread until it now frequently observed throughout the panhandle and central Florida. Tropical spiderwort is currently listed by the USDA as appearing in 12 Florida counties; however, this number is likely to be far greater.

Tropical spiderwort is an aggressive weed that produces aerial (above ground) and subterranean (below ground) flowers. This results in viable seed being produced both above and below ground.

Tropical spiderwort also possesses the ability to root at the nodes and can be propagated from cut stems. Therefore, light cultivation can often break plant parts and increase the area of infestation.
Although tropical spiderwort is difficult to control, early identification and proactive management can greatly reduce its impact on crop yields.

\section{Identification}

Tropical spiderwort has often been confused with spreading dayflower (Comellina diffusa) and asiatic dayflower (C. communis). However, there are three characteristics that separate tropical spiderwort from the other dayflowers:

1. Presence of leaf hairs--Dayflower species possess a thick, waxy, leaf that lacks hairs (glabrous). Tropical spiderwort, on the other hand, will often produce hairs on the young leaves and petioles.

2. Flower color--The flower color of many dayflower species is blue, while tropical spiderwort is more purple/lavender.

1. This document is SS-AGR-223, one of a series of the Agronomy Department, Florida Cooperative Extension Service, Institute of Food and Agricultural Sciences, University of Florida. Published May 2004. Visit the EDIS Web Site at http://edis.ifas.ufl.edu.

2. J.A. Ferrell, assistant professor, Agronomy Department; G. E. MacDonald, assistant professor, Agronomy Department; B. J. Brecke, professor, Agronomy Department, West Florida REC-Milton, FL; Florida Cooperative Extension Service, Institute of Food and Agricultural Sciences, University of Florida, Gainesville, FL 32611.

The use of trade names in this publication is solely for the purpose of providing specific information. UF/IFAS does not guarantee or warranty the products named, and references to them in this publication does not signify our approval to the exclusion of other products of suitable composition.

The Institute of Food and Agricultural Sciences (IFAS) is an Equal Employment Opportunity - Affirmative Action Employer authorized to provide research, educational information and other services only to individuals and institutions that function without regard to race, creed, color, religion, age, disability, sex, sexual orientation, marital status, national origin, political opinions or affiliations. For information on obtaining other extension publications, contact your county Cooperative Extension Service office. Florida Cooperative Extension Service / Institute of Food and Agricultural Sciences / University of Florida / Larry R. Arrington, Interim Dean 


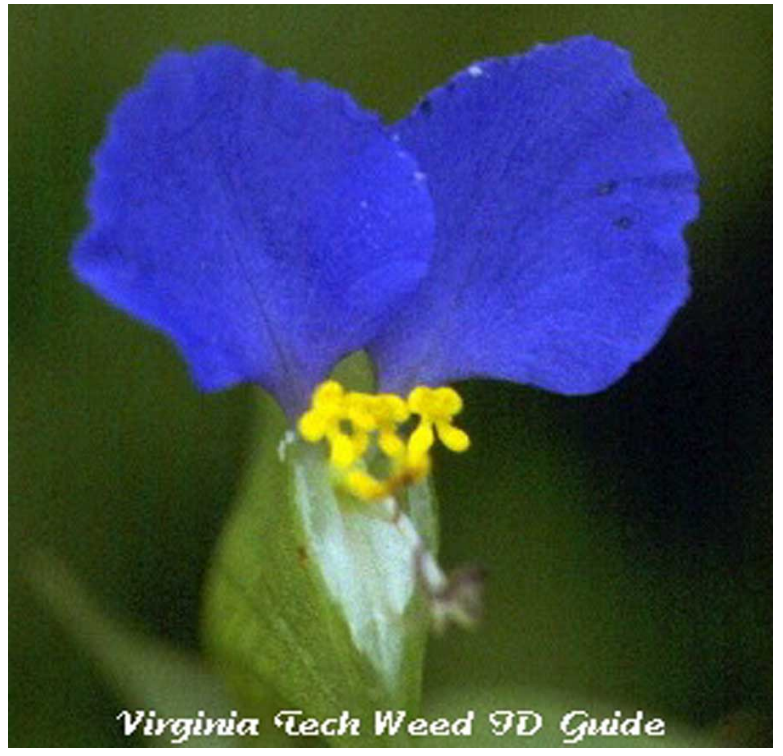

Figure 1. Common or Asiatic Dayflower: Commelina communis. Credits: Virginia Tech Weed Identification Guide

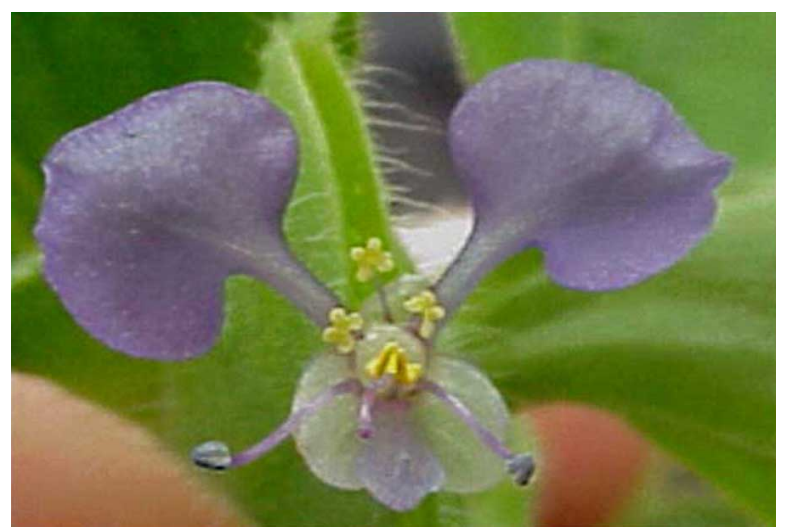

Figure 2. Tropical spiderwort (Commelina benghalensis, L.). Note leaf hairs, purple/lavendar flower.

\section{Root structure--Unlike all other dayflower species, tropical spiderwort produces underground flowers. These flowers are easily seen by examining the roots. These flowers will appear as "swollen nodes".}

\section{Control}

It has been questioned why tropical spiderwort has suddenly emerged as a problem weed. Although the exact answer to this question is currently unknown, it is assumed that tropical spiderwort simply grows better in our relatively new crop production systems. In recent years there has been more reliance on Roundup (or other glyphosate containing products) for weed control and less tillage. Glyphosate, while controlling many weed species, shows only marginal control, with control decreasing

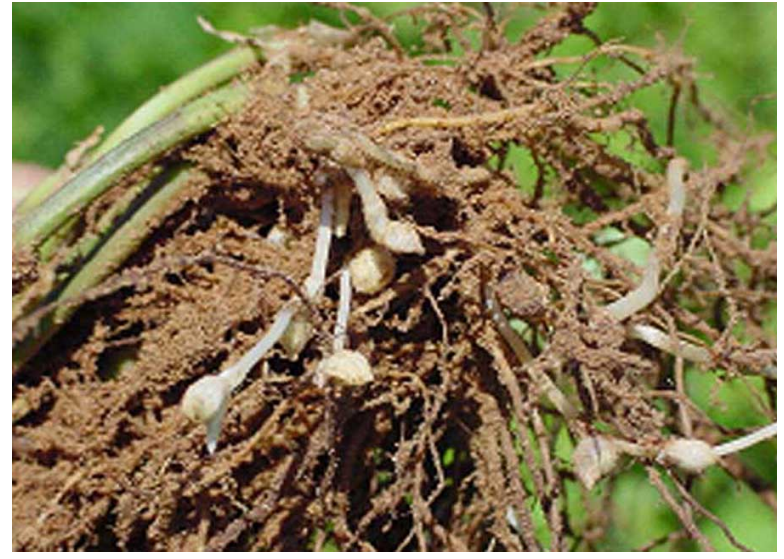

Figure 3. Tropical spiderwort roots showing swollen nodes.

on larger plants. Tropical spiderwort then has an ideal environment to grow after glyphosate eliminates competition from other weeds. Additionally, conservation tillage does not appear to impact tropical spiderwort germination and emergence since seeds or stems are not incorporated deep within the soil profile.

Although current crop management schemes seem to be conducive to tropical spiderwort propagation, management techniques have been developed to reduce its growth and spread.

\section{Cotton}

One difficulty in controlling tropical spiderwort is tolerance to applications of Roundup (or other glyphosate-containing products). Although Roundup can control tropical spiderwort when applied to 1-2" weeds, the lack of soil residual activity will often result in approximately $50 \%$ control by late season. Therefore, other herbicides must be included to improve control and provide soil residual activity. The addition of Staple or Dual II Magnum has been shown to improve tropical spiderwort control over glyphosate alone when applied early postemergence. However, adding $1.33 \mathrm{pt} / \mathrm{A}$ of Dual II Magnum to glyphosate is currently the best control option. Glyphosate + Dual will often provide near $80 \%$ control. However, Dual will only control plants that have not yet emerged, so applications must be made early in the growing season to be effective. It must also be noted that Dual II Magnum will commonly cause leaf burn when applied to small cotton, but recovery will often occur within 7 days of application. Additionally, Dual II Magnum 
CANNOT be applied prior to cotton emergence or severe cotton injury will result.

Post-directed applications may also be necessary if large populations of tropical spiderwort exist. The key to controlling emerged plants is early applications to small weeds. Mid-season applications of Roundup + Aim or MSMA + Direx provided 80 and $83 \%$ control, respectively. However, by delaying applications until layby (treating larger plants), Roundup + Aim provided only $42 \%$ control and MSMA + Direx 64\%.

Dual II Magnum will be the foundation of tropical spiderwort control programs. However, Dual II Magnum applied early postemergence will generally not be sufficient for season-long control. Therefore, 1 to 2 post-directed applications targeting small plants will generally be most effective to control escaped plants. The use of Direx or Caparol might be preferred to add additional soil-residual activity and increased weed spectrum.

\section{Peanuts}

Controlling tropical spiderwort in peanuts will require multi-step management practices that includes both cultural and herbicidal means. Implementing twin-row planting is one cultural practice that has been shown to improve tropical spiderwort control by $8 \%$ when averaged over several herbicide combinations. This is due to more rapid cover of the soil surface with twin rows than peanuts planted in single rows. The coverage will shade the soil surface and interfere with weed seed germination and emergence.

A successful herbicide program, as in cotton, will likely require an early-season application of Dual II Magnum. Preemergence applications of Dual II Magnum are not as effective. However, data collected in Florida and Georgia have shown that Gramoxone (5.5 oz/A) + Dual II Magnum (1.33 $\mathrm{pt} / \mathrm{A})$ will provide approximately $90 \%$ control when applied at-cracking. Gramoxone + Dual II Magnum may be applied up to 28 days after cracking, but early applications (7 to 14 days after cracking) will generally provide better weed control and reduce peanut injury.
Tropical spiderwort control from mid- or late-season herbicide applications have proved to be inconsistent and are directly related weed size at time of treatment. Cadre or Classic + 2,4-DB can provide some control if applied when tropical spiderwort is small. However, these herbicides should be used as part of a control program that contains Gramoxone + Dual II Magnum.

\section{Conclusion}

Tropical spiderwort is a highly competitive and difficult-to-control weed that is relatively new to crop producers in Florida. However, effective control can often be attained if early scouting, cultural, and herbicidal management schemes are implemented. In extreme conditions deep tillage may be helpful, but this should be used only if herbicidal and cultural management programs have proved ineffective.

\section{Acknowledgements}

The authors of this publication thank Dr. Scott Hagood, Extension Weed Specialist, Virginia Polytechnic Institute, for providing the image of common dayflower. The authors also acknowledge the assistance of Drs. A. Stanley Culpepper and Eric Prostko, Extension Weed Specialists, University of Georgia, for experimental data and images of tropical spiderwort. 